\title{
HUMANIZAR-SE PARA HUMANIZAR O OUTRO: EXPERIÊNCIAS EDUCATIVAS NO PROEJA
}

\author{
ALDO REZENDE \\ Instituto Federal de Educação, Ciência e Tecnologia do Espírito Santo (IFES), Vitória, Espírito \\ Santo, Brasil \\ Edna Castro de Oliveira \\ Universidade Federal do Espírito Santo (UFES), Vitória, Espírito Santo, Brasil \\ ELIESÉR TORETTA ZEN \\ Instituto Federal de Educação, Ciência e Tecnologia do Espírito Santo (IFES), Vitória, Espírito \\ Santo, Brasil \\ MARIA José de ReSEnde FerReIRA \\ Instituto Federal de Educação, Ciência e Tecnologia do Espírito Santo (IFES), Vitória, Espírito \\ Santo, Brasil
}

\begin{abstract}
Resumo: O artigo explicita as vivências dos estudantes do Proeja do Ifes nas atividades que compõem os seminários de Filosofia e Sociologia. Apropriamo-nos dos aportes teórico-metodológicos da sistematização de experiências para dar visibilidade às ações educativas exercitadas com os sujeitos da EJA. A produção dos dados, organizados por meio de fontes documentais, constituídos pelos registros das atas das reuniões pedagógicas e de planejamento, das memórias dos diários de campo dos pesquisadores e dos registros fotográficos e audiovisuais, apontam para o protagonismo dos estudantes do Proeja. A prática do diálogo freireano foi exercitada na produção coletiva dos seminários e nos diversos movimentos da ação educativa, que vislumbram a concretude da integração curricular nas perspectivas da formação humana integral e da educação libertária.
\end{abstract}

Palavras-Chave: Diálogos. Formação Humana. Construção Coletiva. Humanização.

\section{INTRODUÇÃO}

Pensar hoje a respeito da educação de jovens e adultos (EJA) remete-nos às reflexões acerca das diretrizes políticas no âmbito da educação pública brasileira, em claro processo de desmantelamento (LIBÂNEO; FREITAS, 2018). Nesse particular, detemos nossa atenção no Programa Nacional de Integração da Educação Profissional com a Educação Básica na Modalidade de Educação de Jovens e Adultos (Proeja), diante das provocações de Machado (2019), quando denuncia o atrofiamento e a desqualificação proposital dessa política pública. Suas ponderações nos exigiram uma leitura atenta dos relatórios oficiais da gestão do Instituto Federal do Espírito Santo (Ifes). O (des)cumprimento dos marcos legais referentes à reserva de vagas para esses sujeitos de direito (BRASIL, 2006; 2008; IFES, 2018) compromete a manutenção do Programa em toda a Rede Federal (BRASIL, 2019; MACHADO, 2019), em clara dissonância com o Plano Anual da Educação (BRASIL, 2018). 
Essas problematizações revelam a negação do direito à educação para significativa parcela da sociedade brasileira. A elas incorpora-se, ainda, o processo de regressão política e social que vivenciamos, de forma aterrorizadora, com a destruição dos frágeis marcos civilizatórios da nação brasileira. Esse processo escancarou os efeitos do obscurantismo e da desigualdade extrema, impetrada por grupos políticos e econômicos de matrizes conservadoras e fundamentalistas, em conluio com grandes corporações associadas aos interesses do capital internacional.

Não obstante esse cenário de destruição deliberada do país em diferentes esferas (na economia, meio ambiente, direitos, saúde, educação, ciência), há, sobretudo, perdas de vidas humanas, decorrente do Coronavírus Sars-CoV-2 (Covid-19). À inexistência de uma política sanitária resultante da negligência genocida e da incapacidade gerencial do governo brasileiro importam ações de resistência. $\mathrm{O}$ movimento de resistir nos impulsiona cotidianamente, como cidadãos, ao enfrentamento da situação de barbárie instalada e à defesa da educação pública, laica, gratuita, inclusiva e de qualidade social para todas e todos. Atentos estamos, na vigilância constante das decisões tomadas pelos entes governamentais, em todas as esferas da administração pública, no que se refere às políticas educativas e, em especial, àquelas que invisibilizam os sujeitos da modalidade da EJA inseridos no Proeja.

É com essa pretensão que apresentamos este texto. Afinal, resistir, nesta conjuntura trágica e desoladora de destruição de vidas humanas, insere-se na nossa esperança em sobreviver ao genocídio institucionalizado. Esperança como necessidade ontológica, segundo nos lembra Freire, quando afirma não entender: "[...] a existência humana e a necessária luta para fazê-la melhor, sem esperança e sem sonho" (FREIRE, 2010 , p. 10). Tomamos também de Freire, além do conceito de esperança, nas diversas possibilidades enunciadas como tarefas de educador engajado, a concepção de resistência. Para esse educador, "[...] resistências - a orgânica e/ou cultural - são manhas necessárias à sobrevivência física e cultural dos oprimidos" (FREIRE, 1996, p. 87).

Esses movimentos de ação e política, tais quais aponta Freire, nos motivam a explicitar as experiências vivenciadas nas práticas educativas de construção coletiva denominadas "Seminário de Filosofia e Sociologia". Nessa oportunidade, o exercício da reflexividade crítica sobre a realidade tornou possível potencializar o protagonismo e a permanente ação de contribuir com a emancipação política dos trabalhadores dos cursos técnicos integrados ofertados por meio do Proeja no Ifes Campus Vitória.

Este texto explicita as contribuições do legado de Paulo Freire para nos ajudar a compreender a realidade educacional vivida num cenário pandêmico e de destruição de direitos sociais e trabalhistas historicamente construídos. Outrossim, também nos remete ao papel transformador da escola por meio da intencionalidade política imbricada nas práticas educativas que desvelam a curiosidade epistemológica (FREIRE, 1996). Ao priorizar a dialogicidade, a construção coletiva, a autonomia e a promoção do pensamento reflexivo-crítico, essas práticas alcançam pressupostos importantes à democratização do conhecimento e à emancipação política dos sujeitos da EJA no Proeja.

$\mathrm{Na}$ sequência, avançamos, do ponto de vista metodológico, tomando a sistematização da experiência enquanto estratégia de investigação, articulada com os 
pressupostos da pesquisa documental. Essas orientações nos auxiliaram a explorar um conjunto de fontes constitutivas dos registros das atas das reuniões pedagógicas e de planejamentos, das memórias dos diários de campo dos pesquisadores e dos registros fotográficos e audiovisuais produzidos nesses eventos. À guisa de finalização, reafirmamos que as políticas direcionadas para os sujeitos da EJA expressam diferentes concepções de sociedade. Nessa disputa permanente, posicionamo-nos na defesa da educação como direito fundamental, universal e inalienável, que se constitui como um dever do Estado.

\section{PRÁXIS EDUCATIVA: DESAFIOS PARA A EMANCIPAÇÃO DOS SUJEITOS DA EJA}

A atualidade do pensamento de Freire se reafirma não somente em virtude do patrulhamento imposto pela atual onda neofascista que assola o país, mas, particularmente, pelas contradições estruturais relacionadas aos processos políticos de outrora, que alimentaram seu pensamento e suas práticas. Eis uma das riquezas do pensamento freireano, pautado pelos pressupostos da pedagogia crítica reveladora das contradições de seu tempo:

Mais uma vez os homens [mulheres], desafiados pela dramaticidade da hora atual, se propõem a si mesmos como problema... Se fazem problema a eles mesmos... O problema de sua humanização, apesar de sempre dever haver sido, de um ponto de vista axiológico, o seu problema central, assume, hoje, caráter iniludível (FREIRE, 1987, p. 29).

Com efeito, torna-se cada vez mais atual a essência do sentido dos pressupostos didáticos da humanização presentes no pensamento desse educador, também revelados por meio da práxis educativa comprometida com o projeto de educação libertária, a ser ressignificado a cada momento histórico. Assim como no período dos anos de chumbo das décadas de 1960 a 1980, na atualidade a barbárie genocida da política institucional e, consequentemente, dos processos de exclusão social que experienciamos, nos impulsionam a refletir acerca desse educador comprometido política e socialmente com os oprimidos.

Os pressupostos da pedagogia libertária de Freire expõem o comprometimento ético-político do educador em sua capacidade de lidar com a realidade dramática marcada pela opressão e pela exclusão, sem, no entanto, perder a ternura quando evoca a necessária humanização dos processos educativos para tomada de consciência e afirmação do permanente movimento de construção de sujeitos históricos. O centro a partir do qual se irradia o processo de humanizaçãodesumanização dos seres humanos está na sua própria inconclusão, conforme sua afirmativa:

É na inconclusão do ser, que se sabe como tal, que se funda a educação como processo permanente [de humanização]. Mulheres e homens se tornaram educáveis na medida em que se reconheceram inacabados. É também na inconclusão de que nos tornamos conscientes e que nos inserta no movimento permanente 
de procura que se alicerça [o processo de humanização] (FREIRE, 1996, p. 58, grifos nossos).

Compreender e apreender a relação didático-pedagógica intrínseca do movimento de inconclusão, enquanto processo em permanente construção, é, com certeza, reconhecer na relação espaço-tempo a sociedade de classes em suas contradições para, no âmbito da educação escolar, refletir sobre as práticas docentes que, em muitos casos, acabam por afirmar as relações desumanizadoras de opressão. Cabe-nos, assim, destacar a dicotomia existente entre a concepção de educação bancária e a concepção de educação fundada na problematização, no exercício de permanente reflexão sobre o mundo, a sociedade, as relações e a existência.

$\mathrm{Na}$ postura do educador que promove a educação bancária torna-se perceptível, em muitos casos, a afirmação de pensamentos e de atitudes maniqueístas que, quando adotadas, conspiram contra a própria ciência e seus fundamentos. Isso ocorre à medida que nega a si próprio como educador e, consequentemente, ao educando, a capacidade de dar conta das inúmeras possibilidades de leitura e interpretação da realidade social. A cegueira mental de posturas e atitudes comprometidas com o obscurantismo embrutecem o ser humano, esterilizam o processo de produção do conhecimento dialógico e coletivo, visto que distorcem a realidade e, por conseguinte, desumanizam os sujeitos, animalizam os seres humanos.

Os pressupostos da relação dialógico-dialética entre educador e educando são fundantes na proposta de educação humanizadora à proporção que buscam, por meio das relações horizontais, promover a emancipação desses sujeitos em sua relação com o "estar", afirmando-se a condição de "seres históricos" comprometidos com a transformação de si e da realidade em suas contradições. Portanto, é a partir das vivências e experiências refletidas e compartilhadas que o processo didáticopedagógico de humanização se realiza em permanente movimento.

A educação humanizadora, por sua vez, funda-se numa relação dialógicodialética entre educador e educando, na dinamicidade por meio da qual ambos aprendem juntos quando tomam consciência de si enquanto seres histórico-sociais. $\mathrm{O}$ diálogo é, nessa relação, uma exigência existencial que possibilita a comunicação e permite ultrapassar o imediatamente vivido. É no reconhecimento mútuo entre educador e educando, entre um saber de experiência feito e vivido, que ambos se tornam sujeitos, tomam consciência, tornam-se protagonistas e humanizam-se.

No alcance possível do projeto de educação humanizadora, o pensamento freireano está intrínseco numa relação indissociável da práxis educativa comprometida com a proposta de formação integral de jovens, adultos e idosos. É uma oportunidade em que os fundamentos filosóficos e epistemológicos iluminam o trabalho como princípio educativo, em sua capacidade de desvelar o ser humano na condição de ser social, histórico, humanizado e humanizador, mesmo quando o obscurantismo se mostra ameaçador e predatório dos atos do pensar, do fazer ciência e das possibilidades de produzir conhecimentos elaborados.

Decerto, no mundo contemporâneo, verifica-se a apoteose do capitalismo no campo das inovações tecnológicas e científicas. Se, por um lado, afirma-se a sua capacidade de restruturação produtiva e de controle social nas mais diversas dimensões 
da vida humana, por outro ele torna ainda maior o fosso entre ricos e pobres, acirrando exponencialmente o crescimento das desigualdades socioeconômicas no âmago das agruras entre inovação e abundância, pobreza e miséria.

O legado de Freire nos impulsiona para a necessidade de reconhecer as contradições dos processos de desumanização da sociedade capitalista e, a partir desse reconhecimento, levar o oprimido a reconhecer seu opressor e os mecanismos de opressão (desumanização). Dessa forma, pode-se elevá-lo à condição de sujeito histórico no processo de tomada de consciência de classe e na luta pela construção de uma sociedade mais justa e igualitária.

A brutal concentração das riquezas produzidas pela humanidade nas mãos de uma minoria ainda persiste na sociedade brasileira e constitui verdadeiro obstáculo ao processo de humanização proposto por Freire (1987). A histórica condição de vulnerabilidade social de significativa parcela da sociedade brasileira permite-nos reconhecer formas de pobreza reveladoras da dívida social, historicamente acumulada, particularmente nos países que, no âmbito da divisão social e internacional do trabalho, tornam-se cada vez mais dependentes e subalternos. Assim, conforme apontado por Santos (2000), é possível destacar três formas de pobreza nos países de economia dependente: a pobreza acidental, a pobreza marginal e a pobreza estrutural. Essa, em sua essência, é indispensável à própria manutenção da situação de desigualdades pautadas pelas relações de dominação e opressão, inerentes ao projeto capitalista de produção e organização social em suas mais diferentes etapas de propulsão.

Ao analisar os dados da Pesquisa Nacional por Amostra de Domicílios de 2019 (PNAD), realizada pelo Instituto Brasileiro de Geografia e Estatística (IBGE) acerca da desigualdade no país, constatou-se que as desigualdades se mantiveram no pior nível da série desde o ano de 2012. Esse índice veio aumentando desde 2015 e manteve o resultado negativo de 2018. Sobre os dados relativos à educação, apurou-se o quantitativo de 11 milhões de analfabetos no país a partir dos 15 anos de idade (BRASIL, 2019).

Mediante a exposição desse quadro de desigualdades, entendemos que a responsabilidade ético-política do educador se faz necessária no sentido de afirmar a educação como um ato de liberdade solidário e compartilhado, a partir do movimento necessário de transformar-se, reconhecendo-se enquanto sujeitos históricos para transformar a realidade social em suas contradições. Reiteramos que a educação deve possibilitar a leitura crítica do mundo, o que implica a denúncia da realidade opressiva e da alienação desumanizadora, cooperando para o anúncio da dignidade do homem e de uma realidade mais justa e democrática.

Assim, a educação, notadamente a EJA, deve possibilitar que os sujeitos indignem-se com os problemas advindos da desigualdade social, apreendendo essa realidade criticamente, como possibilidade para sua transformação. Sem dúvida, nesse cenário de exacerbadas desigualdades sociais, torna-se iminente considerar o comprometimento dos educadores, quando, na condição de sujeitos mediadores dos processos de enfrentamentos, assumem o papel de intelectuais orgânicos. A concretude da práxis é indispensável no permanente movimento que objetiva pela tomada de consciência, pela afirmação do protagonismo e da emancipação dos educandos, a partir da reflexão crítica sobre a própria realidade social para, então, transformá-la. 
Na perspectiva da pedagogia crítica, a práxis educativa libertária, pressuposto indispensável para a compreensão da existência, afirma-se a partir da relação dialética entre subjetividade e objetividade, ação e reflexão. Não se trata de uma simples teoria da ação. A efetiva reflexão deve sempre levar à ação, desde que esta não se configure como simples ativismo, e, assim, ganhe concretude por meio do movimento reflexivo crítico (FREIRE, 1987). Trata-se, no nosso entendimento, do elo possível e desejado entre a educação e sua capacidade humanizadora, por meio das relações tecidas entre educador e educando, com o propósito de realizar, de forma reflexiva e crítica, o desvelamento da realidade em sua totalidade social.

Dessa forma, a organicidade do processo de produção do conhecimento reitera a máxima freireana de que "ninguém liberta ninguém, ninguém se liberta sozinho: os homens se libertam em comunhão" (FREIRE, 1987, p. 27). Emergem, então, as possibilidades de uma proposta de educação humanizadora, libertária e capaz de suscitar a construção de um novo projeto de vida em sociedade.

\begin{abstract}
A relação de organicidade a que nos referimos implica a posição cada vez mais conscientemente crítica do homem diante do seu contexto para que nele possa interferir. Não há organicidade na superposição, em que existe a possibilidade de ação instrumental. Da mesma forma, a organicidade do processo educativo implica a sua integração com as condições do tempo e do espaço a que se aplica para que possa alterar ou mudar essas mesmas condições. Sem esta integração o processo se faz inorgânico, superposto, inoperante (FREIRE, 2001, p. 11).
\end{abstract}

Em especial, tratando-se da proposta de pensar o papel do educador na EJA, a organicidade ganha concretude por meio do permanente movimento de reflexão crítica da realidade, em suas contradições e conflitos, como já afirmado. Um desafio que se impõe cada vez mais, tendo em vista o avanço do fundamentalismo religioso em sua capacidade de dominação e alienação. Intenta-se, portanto, construir na relação pedagógica, solidária e dialógica a superação do estágio de alienação e da opressão, essência da pedagogia crítica de Freire em sua relação indissociável da práxis educativa libertária.

O alcance da proposta de educação humanizadora reside também na capacidade de diálogo do educador com o educando. À medida que tira os educandos nesse particular, jovens, adultos e idosos - da condição de meros espectadores, sempre na defensiva e com medo de não dar conta de apreender e de não corresponder aos preceitos da educação humanizadora, essa os torna centrais na produção do conhecimento, por meio de estratégias pedagógicas dialógicas, capazes, assim, de conectar os educandos com o mundo a partir do próprio sujeito.

Como projeto político, o exercício da educação humanizadora ganha concretude, também, por meio da práxis educativa em sua capacidade revolucionária de romper com a dicotomia do pensamento e da ação, fazendo com que esses movimentos ocorram simultaneamente e dialeticamente. Nessa perspectiva, a leitura crítica da realidade, a partir dos sujeitos em sua relação com o mundo, como parte do mundo em 
REZENDE, A.; OLIVEIRA, E. C. de ZEN, E. T.; FERREIRA, M. J. de R

suas contradições, permite intervenções comprometidas com a emancipação, com a libertação. Um exercício revolucionário pautado pela práxis educadora libertária capaz de promover a superação, pelo próprio oprimido, das contradições das relações oprimido e opressor, como nos é apontado por Freire (1987, p. 28):

Para que esta luta tenha um significado, os oprimidos não devem, na tentativa de recuperar a sua humanidade (que é uma forma de criá-la), tornarem-se por sua vez opressores dos opressores, mas sim restauradores da humanidade de ambos. Essa, então, é a grande tarefa humanista e histórica dos oprimidos: libertarem a si e aos seus opressores.

Engendrada na luta pela libertação, a dialeticidade do movimento de superação da relação oprimidos-opressores está no centro da proposta freireana de educação humanizadora, que passa pelo compromisso ético-político de educadores que, humanizando-se, solidariamente, humanizam os educandos. A práxis educativa transformadora se revela na síntese do processo de construção do conhecimento indutor do movimento comprometido com a tomada de consciência reflexiva e crítica, e é capaz, portanto, de potencializar o protagonismo e a emancipação política dos sujeitos, em especial dos sujeitos da modalidade de educação de jovens, adultos e idosos, inseridos no Proeja.

OS MOVIMENTOS DA PESQUISA: PRÁXIS EDUCATIVA-HUMANIZADORAS EXPERIENCIADAS NO PROEJA

Ao nos lançarmos nesse desafio de visibilizar os processos formativos dos sujeitos do Proeja, materializados nas atividades que compõem os seminários de Filosofia e Sociologia, a partir da sistematização da experiência como instrumento metodológico (MACHADO; PALUDO, 2010), respaldamo-nos na proposição de que sistematizar é:

Apropriar-se da experiência vivida e dar conta dela, compartilhando com os outros o aprendido. Interpretação crítica de uma ou várias experiências que, a partir de seu ordenamento e reconstrução, descobre ou explicita a lógica do processo vivido, os fatores que intervieram no processo, como se relacionaram entre si e porque o fizeram desse modo (JARA HOLLIDAY, 2006, p. 22).

Esse delineamento metodológico nos conduziu a "observar, escutar, registrar, interpretar, desconstruir e descrever o processo e as análises" (MESSINA; OSÓRIO, 2016, p. 618 , tradução nossa) para explorarmos as experiências vividas e, subsidiados por esses delineamentos, produzirmos "conhecimentos a partir da experiência da prática" (MEJíA JIMENEZ, 2009, p.21).

Esse processo de (re)construção do conhecimento, a partir das ações educativas dos sujeitos do Proeja, contribuiu para a compreensão da realidade educacional que se efetiva em um conjunto de relações complexas, mediante o processo de reflexão crítica acerca das nossas experiências. 


\begin{abstract}
Por isso é que, na formação permanente dos professores, o momento fundamental é o da reflexão crítica sobre a prática. É pensando criticamente a prática de hoje ou de ontem que se pode melhorar a próxima prática. O próprio discurso teórico, necessário à reflexão crítica, tem de ser de tal modo concreto que quase se confunda com a prática. O seu "distanciamento" epistemológico da prática enquanto objeto de sua análise, deve dela "aproximá-lo" ao máximo. Quanto melhor faça esta operação tanto mais inteligência ganha da prática em análise e maior comunicabilidade exerce em torno da superação da ingenuidade pela rigorosidade. Por outro lado, quanto mais me assumo como estou sendo e percebo a ou as razões de ser de porque estou sendo assim, mais me torno capaz de mudar, de promover-me, no caso, do estado de curiosidade ingênua para o de curiosidade epistemológica. Não é possível a assunção que o sujeito faz de si numa certa forma de estar sendo sem a disponibilidade para mudar. Para mudar e de cujo processo se faz necessariamente sujeito também (FREIRE, 1996, p. 21).
\end{abstract}

No entendimento dessa proposição de sistematização da experiência enquanto estratégia de investigação, associamos as orientações da pesquisa documental (CELLARD, 2008), que, articuladas, deram suporte para a produção dos dados, à medida que nos adentramos nas leituras dos planejamentos docentes, das atas e das memórias das reuniões pedagógicas e de planejamento. O acesso aos diários de campo dos pesquisadores envolvidos nas edições dos seminários temáticos, dentre outros registros documentais, como as fotografias e os vídeos, nos possibilitaram a visibilidade e o exercício da leitura propositiva das práticas educativas no Proeja, construídas de forma coletiva e dialógica pelos sujeitos na organização e na produção dos referidos eventos.

Os seminários temáticos propostos pelas disciplinas Filosofia e Sociologia, ofertadas aos estudantes dos cursos técnicos integrados do Proeja Ifes Campus Vitória, apresentam-se como uma significativa oportunidade de afirmação da práxis educativa humanizadora, que, pautada pelo incentivo às atividades de ensino e pesquisa, traz o estudante para o centro do processo de construção do conhecimento. Trata-se, portanto, de uma prática pedagógica que se efetiva também por meio da problematização das vivências e das experiências dos estudantes da EJA, desvelando, assim, o sentido da práxis humanizadora, já que corrobora o protagonismo e, por conseguinte, alimenta e fortalece o movimento dialético e permanente pela emancipação dos diferentes sujeitos envolvidos. Outrossim,

Neste sentido e não só neste, mas em outros também, nossas relações com os educandos, exigindo nosso respeito a eles, demandam igualmente o nosso conhecimento das condições concretas de seu contexto, o qual os condiciona. Procurar conhecer a realidade que vivem nossos alunos é um dever que a prática educativa nos impõe: sem isso não temos acesso à maneira como pensam, dificilmente então podemos perceber o que sabem e como sabem (FREIRE, 1997, p. 53). 
A diversidade de temas e temáticas e os respectivos desdobramentos, sempre alinhados com os princípios e fundamentos epistemológicos da Sociologia e da Filosofia, induzem ao movimento do pensamento e motivam diálogos possíveis com as demais áreas do conhecimento na proposição da integração curricular. Cabe enfatizar que o permanente exercício de busca pela integração curricular não se estabelece enquanto regra. As totalizações alcançadas decorrem dos movimentos realizados a partir da capacidade de mobilização dos sujeitos envolvidos no processo de construção do conhecimento (ARAÚJO; FRIGOTTO, 2015).

O intuito de busca pela problematização das vivências e das experiências dos estudantes, durante o processo de construção do conhecimento relacionado às etapas de realização dessa ação educativa, reflete também a densidade e intensidade da práxis educativa humanizadora pretendida e alcançada. Nesse ínterim, a intencionalidade política do educador ganha notoriedade por meio de sua capacidade de promover a reflexividade, a articulação e a mobilização dos sujeitos envolvidos - educandos e educadores, nas atividades de ensino e de pesquisa no desenvolvimento da ação educacional decorrente.

Dentre as inúmeras experiências já realizadas, intentamos, na sequência, destacar algumas delas e, dessa forma, contribuir com o movimento de "fuga da abstração", ou seja, de materialização das contribuições teóricas e conceituais relacionadas à educação humanizadora de Freire, por meio da práxis educativa em suas possibilidades e alcances. A partir da exploração das fontes documentais, destacamos diferentes excertos que dão visibilidade a esses movimentos anunciados:

\begin{abstract}
A proposição da atividade semestral que denominamos de seminário temático de Filosofia e Sociologia começa no início de cada semestre, com os professores dessa área dialogando com os colegas docentes e estudantes acerca dos temas possíveis a serem abordados. Após essa consulta, os docentes reúnem e definem as diretrizes de como as temáticas, as leituras, os responsáveis por cada turma e as dinâmicas que irão desenvolver até a materialização da ação educativa no dia de realização do seminário. Há um envolvimento de toda Coordenação do Proeja nessa tarefa até o dia marcado para o acontecimento. No dia, um lanche é preparado e servido, para a recepção dos estudantes, por docentes e discentes. Logo após, há um encontro de todos os grupos e respectivos professores responsáveis pela produção e apresentação do que foi organizado de forma coletiva em sala de aula. Essas apresentações se dão de diferentes formas: nas salas de aulas ou no próprio espaço do teatro. A intenção é que os estudantes interajam entre eles, para que todos possam apresentar e conhecer o que todos os grupos realizaram. Finalizamos com um outro lanche e um sorteio de brindes doados por toda a comunidade escolar. A avaliação da atividade é feita em outro momento, no espaço da sala de aula. É uma ação do Proeja que está inserida no calendário escolar, no PPC e na carga horária dos cursos técnicos integrados de Guia de Turismo e Hospedagem. A interação e o diálogo entre docentes e estudantes revelam-se muito profícuos (PROFESSORA, EXCERTO DO DIÁRIO DE CAMPO, 2019).
\end{abstract}


A práxis educativa ganha materialidade a partir dos diálogos iniciais, que constituem pressupostos metodológicos na definição de estratégias pedagógicas inovadoras. À proporção que se concretizam, as estratégias contribuem para o movimento de construção do projeto de forma solidária e compartilhada.

\begin{abstract}
Um dos encontros considerados muito instigantes diz respeito à proposição de repensar a dinâmica do seminário tradicional com a presença de um palestrante. A ideia foi que a convidada encaminhasse antecipadamente o texto da palestra, que foi explorado em sala de aula por todos os professores envolvidos. $\mathrm{Na}$ exploração desse texto, feito por diversos professores em diferentes aulas, muitas indagações feitas pelos estudantes foram endereçadas à palestrante, que habilmente, no dia da palestra, foi apresentando as ideias propostas pela temática e respondendo a cada estudante, as provocações feitas por eles. Foi uma das palestras mais participativas e dinâmicas de todas as nossas experiências do Seminário (COORDENAÇÃO DO PROEJA, ATA DA REUNIÃO, 2018).
\end{abstract}

Faz-se importante apresentar a sistematização de uma experiência do Seminário de Filosofia e Sociologia, realizado no primeiro semestre de 2019, que teve como tema: Política, desigualdade e um projeto de nação. De acordo com o relato, registrado em diário de campo, o subtema: o golpe de 2016, retrocesso democrático e aprofundamento das desigualdades, foi definido a partir das intensas discussões relacionadas ao resultado das eleições presidenciais de 2018 , quando a divisão de opiniões e posições políticas esbarrou na polarização entre dois grupos distintos. Ainda de acordo com relatos do professor, essas duas formas de explicitar a polarização relacionada às posições políticas distintas, embora não muito bem fundamentadas, inicialmente dificultaram o processo de coesão da turma, mediante a proposta de definir um projeto de trabalho a partir do subtema definido, de forma polêmica, pela maioria dos estudantes.

\begin{abstract}
A partir das reflexões sobre o conceito de democracia, foi possível, por meio do diálogo, reduzir o grau de intolerância e enfrentamento entre os dois grupos para assim, construir uma terceira via capaz de dar conta de preencher a lacuna referente à ausência de fundamentação capaz de sustentar as posições distintas dos grupos. Na medida em que os estudantes foram assimilando os nexos presentes nas argumentações de base histórica, socioeconômica, cultural ética e política, a compreensão sobre a importância de aprender a contextualizar, permitiu a abertura de espaço para potencializar ainda mais o diálogo e tornar possível a convivência e o compromisso com a produção do trabalho. Ao compreenderem que mesmo em posições diversas, todos e todas tinham uma história em comum e uma tarefa escolar para dar conta: construir e apresentar o trabalho publicamente. Contudo, o desafio estava posto: garantir pelo menos a boa
\end{abstract}


REZENDE, A.; OLIVEIRA, E. C. de ZEN, E. T.; FERREIRA, M. J. de R.

convivência entre o grupo minoritário e o grupo maioritário de estudantes, que afirmava ter sido o resultado das eleições de 2018, resultado de um processo de golpe político, jurídico e midiático, iniciado com a deposição da presidenta Dilma Rousseff em 2016 (PROFESSOR, EXCERTO DO DIÁRIO DE CAMPO, 2019).

A partir do relato, a polarização constatada pelo professor em relação aos estudantes reflete uma conjuntura política historicamente marcada pela ruptura da linha tênue da democracia em alguns de seus princípios fundantes: ética e tolerância. Aos integrantes das classes subalternas, a exemplo de parte significativa de estudantes jovens, adultos e idosos do Proeja, a ausência de reflexão crítica sobre a realidade, por vezes comum a todos e todas, encontra eco nas narrativas dos fundamentalistas religiosos a serviço dos interesses das elites brasileiras. São religiosos e pregadores que viralizam a ideologia do individualismo e da promessa de prosperidade seletiva e meritocrática, em conformidade com o grau de subserviência; a densidade e a exacerbação da fé manifestam-se. Vê-se, assim, um declarado mecanismo de controle social dos pobres, cada vez mais desarticulados enquanto corpo social e, portanto, desumanizados. Esse comportamento alienante tem ganhado expressão tanto nas posições políticas declaradas, como também na própria negação da ciência em seus princípios indispensáveis à compreensão do conhecimento elaborado.

O desafio de educar como prática para a liberdade vai se tornando cada vez mais complexo e instigante. Em convergência com as concepções freireanas, a tomada de consciência é um processo lento, que decorre da capacidade do educador de conseguir inserir-se no universo de contradições do educando, para, de forma solidária e dialógica, construir as interrogações capazes de fazer acontecer o movimento do espírito reflexivo e apontar para novas possibilidades de compreensão e apreensão da realidade. É um trabalho cotidiano no campo das ideias que envolve a amorosidade, a paciência e a tolerância, exercícios indispensáveis para problematizar e ressignificar a própria existência e a do outro. Um processo necessário de humanização recíproca.

Ainda conforme apontado pelo educador, nas atividades de produção do trabalho junto aos estudantes da turma responsável pela apresentação do subtema: $O$ golpe de 2016, retrocesso democrático e aprofundamento das desigualdades, o conhecimento interdisciplinar, a capacidade de contextualizar e a sensibilidade de conduzir o processo didático-pedagógico, de forma propositiva e compartilhada, foram algumas das importantes estratégias adotadas para alcançar o resultado positivo na produção e apresentação do trabalho pelos estudantes, por meio de grupos de atividades com recortes temáticos interconectados ao subtema em sua totalidade de apreensão.

De forma criteriosa e pedagógica, uma parte dos estudantes contrários à narrativa do golpe político, jurídico e midiático de 2016 e sua influência nos resultados das eleições presidenciais de 2018, formaram o grupo $n^{\circ} 1$, incumbidos de pesquisar e preparar uma apresentação sobre o sentido da democracia a partir da Constituição Federal de 1988. A outra parte dos estudantes formou o grupo $n^{\circ} 2$, para pesquisar e apresentar as conquistas sociais, políticas, econômicas e culturais, ocorridas a partir dos anos de 1990 a 2016, na medida em que essas conquistas, apontadas pela CF de 
1988, passaram a ser paulatinamente regulamentadas por meio de Leis específicas, até o ano em que Dilma Rousseff foi destituída da Presidência da República. De forma articulada, um outro grupo de estudantes, em diálogo com os grupos 1 e 2, ficou responsável pela defesa da narrativa de golpe político, jurídico e midiático em 2016, tendo como pressuposto central, a disputa dos grupos políticos e econômicos nacionais e estrangeiros pelo pré-sal. Este trabalho foi o divisor de águas, pois desencadeou a problematização apresentada por outros dois grupos que ficaram responsáveis em relatar o desmonte das políticas sociais, o agravamento da crise econômica, o aumento do número de desempregados, e a silenciosa entrega do pré-sal sob a falácia da corrupção na Petrobrás, enquanto mecanismo de massificação do processo de controle político e ideológico da massa. Por fim, foram apresentados estudos sobre os retrocessos verificados na realidade política, econômica e social brasileira. O trabalho foi montado de forma criativa, em todo o espaço da sala de aula. Cartazes, painéis, imagens, desenhos, projeções de vídeos, sempre acompanhados de estudantes durante as apresentações aos visitantes. De forma visível, notou-se que o objetivo do sucesso do trabalho era de toda a turma. No dia do seminário, os visitantes percorreram o espaço da sala na sequência das apresentações realizadas pelos estudantes da turma. No final, os visitantes tinham o direito de votar secretamente para confirmar ou negar a existência do golpe político, jurídico e midiático, que influenciou nos resultados das eleições presidenciais de 2018, definindo um novo panorama de retrocessos, contradições e conflitos. $O$ resultado favorável à narrativa do golpe deixou de ser uma posição de um grupo para tornar uma posição democraticamente aceita a partir do voto, do exercício da cidadania, princípio básico da vida democrática (PROFESSOR, EXCERTO DO DIÁRIO DE CAMPO, 2019).

Nas entrelinhas do relato apresentado, dois movimentos estratégicos são relevantes porque, por um lado, instigam o desenvolvimento da pesquisa de forma problematizadora e, assim, promovem a conexão do estudante com sua realidade de maneira crítica, fundamentada. Por outro lado, a estratégia de ações integradas em permanentes diálogos entre os grupos de estudos e pesquisas responsáveis pela produção do trabalho, que adquire então um formato único, totalizado, na perspectiva do tema central, passou a representar o resultado do esforço coletivo. De acordo com Freire (2010, p. 94):

Nada ou quase nada existe em nossa educação, que desenvolva no nosso estudante o gosto da pesquisa, da constatação, da revisão dos "achados" - o que implicaria no desenvolvimento, da consciência transitivo-crítica. Pelo contrário, a sua perigosa superposição à realidade intensifica no nosso estudante a sua consciência ingênua. A própria posição de nossa escola, de modo geral, acalentada ela mesma pela sonoridade da palavra, pela 
REZENDE, A.; OLIVEIRA, E. C. de; ZEN, E. T.; FERREIRA, M. J. de R.

memorização dos trechos, pela desvinculação da realidade, pela tendência a reduzir os meios de aprendizagem às formas meramente nocionais, já é uma posição caracteristicamente ingênua.

Decerto, a pesquisa orientada à problematização, a partir dos temas, de alguma forma, direta ou indiretamente, dialoga com a realidade dos estudantes. O protagonismo se revela na sutileza das estratégias adotadas em conjunto com o incentivo à pesquisa e, com certeza, na transposição do estágio da opinião "cega" para um novo horizonte de certezas e incertezas, que permite transpor do pensar para o refletir e, por conseguinte, dar conta da realidade ressignificada. Além desse exemplo de práxis educativa, outras experiências ganharam concretude e, na sequência de suas realizações, a cada seminário, novas estratégias pedagógicas foram definidas de forma colaborativa, permitindo reconhecer, no compromisso ético-político do educador, sua capacidade de mediar para transformar-se e transformar o outro. Assim a utopia se realiza, no necessário e incansável compromisso de humanizar-se: o educador é capaz de humanizar o outro no permanente movimento de problematizar, tomar consciência e revolucionar-se para transformar a realidade.

\section{CONSIDERAÇÕES FINAIS}

Para finalizar este texto é imprescindível, mais uma vez, fazer o exercício de contextualização, no sentido de denunciar a situação do povo brasileiro, em sua expressiva maioria em condições de desemprego, informalidade e desalento, assim como de recrudescimento da situação de fome e de miséria. É nesse contexto que assistimos ao avanço da ideologia neofascista marcada, principalmente, pelo obscurantismo e pelo fundamentalismo político, econômico e sociocultural, no campo das seitas religiosas e da imposição de costumes e comportamentos sociais conservadores. Os acontecimentos relacionados ao vergonhoso processo de desmonte dos direitos sociais historicamente conquistados, assim como a destruição do estado democrático de direito e de permanentes iniciativas de criminalização da política brasileira também são consequências da perversidade dessa ideologia.

Nesses termos, a escola tornou-se alvo de permanentes ataques, não apenas no tocante à redução de investimentos, como, notadamente, no movimento orquestrado de desqualificação do conhecimento científico e, por conseguinte, do papel do educador como agente central do processo de produção do conhecimento no âmbito da educação escolar.

Indiscutivelmente, em tempos tão sombrios, reiterar os princípios filosóficos e políticos do pensamento de Freire é, com certeza, criar trincheiras de resistência capazes de potencializar o movimento reflexivo e problematizador da realidade de milhões de brasileiros diante do intenso processo de desumanização em curso. Processos que cada vez mais expõem a dramática lacuna entre pobres e ricos, além das inovações no campo da dominação ideológica e do controle social exercido pelas classes dirigentes nas esferas política e econômica.

O reconhecido processo de desumanização em curso desvela a exacerbada relação de opressão que, por vezes, ressignificada em suas estratégias, faz aumentar 
vertiginosamente o número de brasileiros subalternos, que se tornam cada vez mais descartados pelo "sistema" em suas sorrateiras formas de promover a situação de pobreza e miséria extrema e absoluta.

Na esfera da educação escolar, dar conta dessas contradições historicamente engendradas nos mais diversos e diferentes estágios de propulsão e afirmação do capitalismo, como modo de produção e estrutura de organização política e sociocultural de classes, permite-nos movimentar o pensamento no sentido da assunção do ato de educar como um ato político, comprometido com a luta de classes no permanente processo de enfrentamentos e de humanização dos subalternos, para, assim, na condição de sujeitos históricos, promoverem a transformação da realidade, mesmo em suas contradições.

A reflexão proposta a respeito das estratégias didático-pedagógicas de atuação no campo das práticas docentes no Proeja evoca a importância da responsabilidade e do compromisso ético-político dos educadores, tendo como referência os pressupostos epistemológicos do pensamento de Freire.

Tratamos da contribuição do pensamento desse educador em sua possibilidade de desnudar o costumeiro sentido romântico da relação dialógico-dialética entre educadores e educandos. Tal postura nos permitirá compreender melhor o significado da ternura e das manifestações de amorosidade que se fazem importantes nessa relação; o cimento necessário capaz de dar consistência ao processo didáticopedagógico de relações horizontais, solidárias e compartilhadas na produção do conhecimento. Uma estratégia pedagógica também capaz de potencializar a luta de classes, a tomada de consciência para, assim, promover a emancipação política dos sujeitos: educadores e educandos.

A compreensão e apreensão sobre os processos de desumanização, cada vez mais presentes no contexto da sociedade de classes, em suas contradições historicamente determinadas, também expõem a vulnerabilidade, ou melhor, a invisibilidade de brasileiras e brasileiros jovens, adultos e idosos que tiveram, ao longo de suas vidas, trajetórias escolares interrompidas. Entendemos já serem por demais reconhecidas as especificidades desses sujeitos, tanto em relação às precárias condições de existência material como, notadamente, quanto à ausência de projetos de educação escolar, que, estruturados em políticas de estado perenes, sejam capazes de assegurar investimentos e, por conseguinte, o direito ao acesso, à permanência e ao êxito de estudantes jovens, adultos e idosos.

A partir da concepção de Freire de educação transformadora e libertária, a sistematização de experiências referentes à práxis educativa-humanizadora, no âmbito da realização de seminários temáticos integrados de Filosofia e Sociologia, envolvendo os discentes do Proeja, fortaleceu a relação entre atividades de ensino e pesquisa. Também demonstrou ser estratégia capaz de promover a valorização dos saberes e do conhecimento científico, importantes para o processo de formação humana e emancipação dos sujeitos envolvidos: educadores e educandos.

A experiência da realização dos seminários temáticos coaduna com o propósito de despertar a responsabilidade e o compromisso ético-político de educadores em suas relações com os educandos, por meio de reflexões sobre questões políticas, sociais, 
REZENDE, A.; OLIVEIRA, E. C. de; ZEN, E. T.; FERREIRA, M. J. de R.

econômicas, culturais, éticas e estéticas, no contexto da sociedade capitalista em suas contradições. Uma oportunidade capaz de realizar o movimento de humanização dos sujeitos envolvidos a partir do reconhecimento e apreensão dos processos de desumanização em curso, com o avanço da ideologia neoliberal, do conservadorismo, da negação da ciência e dos movimentos permanentes na tentativa de desqualificar o papel da escola e o lugar do docente na educação escolar.

As experiências relatadas dos seminários de Filosofia e Sociologia, desenvolvidas com as turmas dos cursos técnicos integrados do Proeja do Ifes Campus Vitória, são sinais de que, além de revelar o compromisso ético-político de educadores, por meio da práxis educativa problematizadora e libertária, corroboram a importância da escola enquanto lugar do pensamento plural, dos saberes e da produção do conhecimento elaborado e, especialmente, da capacidade dos educadores em humanizar-se, para humanizar os que brutalmente desumanizam os pobres para tornálos descartáveis.

\section{HUMANIZE YOURSELF TO HUMANIZE THE OTHER: EDUCATIONAL EXPERIENCES IN PROEJA}

ABSTRACT: This study explains the experiences of Proeja students at Ifes during the activities proposed by the Philosophy and Sociology seminars. The theoretical and methodological contributions of the systematization of experiences were appropriated in order to make the educational actions built with EJA's students visible. The data production, organized through a documentary sources, were constituted by the records of the pedagogical and planning meetings, field journal notes, photographs and audiovisual records, that indicate the protagonism of Proeja's students and the practice of Freire's dialogue, exercised in the collective production of seminars and in the various movements of educational action that envision the concreteness of curricular integration, in the perspective of integral human development and libertarian education.

KEYWORDS: Dialogues. Human Formation. Collective Construction. Humanization.

\section{HUMANIZARSE PARA HUMANIZAR AL OTRO: EXPERIENCIAS EDUCATIVAS EN PROEJA}

RESUMEN: El artículo muestra las experiencias de los alumnos del Proeja do Ifes en las actividades que componen los seminarios de Filosofía y Sociología. Nos apropiamos de los aportes teóricos y metodológicos de la sistematización de experiencias para visibilizar las acciones educativas ejercidas con los sujetos de la EJA. La producción de los datos, organizada a través de fuentes documentales conformado por las actas de las reuniones pedagógicas, reuniones de planificación, las memorias registradas en los diarios de campo de los investigadores y los registros fotográficos y audiovisuales, apuntan al protagonismo de los estudiantes de Proeja y la práctica del diálogo de Freire, ejercido en la producción colectiva de seminarios y en los diversos movimientos de acción 
Humanizar-se para humanizar o outro: experiências educativas no Proeja

educativa que vislumbran la concretización de la integración curricular, en la perspectiva de la formación humana integral y la educación libertaria.

PALABRAS CLAVE: Diálogos. Formación Humana. Construcción Colectiva. Humanización.

\section{REFERÊNCIAS}

ARAUJO, R. M. de L.; FRIGOTTO, G. Práticas pedagógicas e ensino integrado. Revista Educação em Questão, Natal, v. 52, n. 38, p. 61-80, maio/ago. 2015.

BRASIL. Lei no 11.892 de 29 de dezembro de 2008. Institui a Rede Federal de Educação Profissional, Científica e Tecnológica, cria os Institutos Federais de Educação, Ciência e Tecnologia, e dá outras providências. Diário Oficial da República Federativa do Brasil, Brasília, 2008.

BRASIL. Ministério da Educação. Instituto Nacional de Estudos e Pesquisas Educacionais Anísio Teixeira. Sinopse Estatística da Educação Básica do INEP. Brasília/DF: INEP. 2019.

BRASIL. Ministério da Educação. Conselho Nacional de Educação. Relatório do 2o Ciclo de Monitoramento das Metas do Plano Nacional de Educação - 2018. Brasília/DF: INEP. 2018.

BRASIL. Decreto № 5.840, de 13 de julho de 2006. Brasília, DF: Presidência da República. Institui, no âmbito federal, o Programa Nacional de Integração da Educação Profissional com a Educação de Jovens e Adultos - PROEJA, e dá outras providências. Disponível em: <http://www.planalto.gov.br/ccivil_03/_Ato2004-2006/2006/Decreto/D5840.htm>. Acesso em: 28 ago. 2019.

CELLARD, A. A análise documental. In: POUPART, J. et al. A pesquisa qualitativa: enfoques epistemológicos e metodológicos. Petrópolis: Vozes, 2008. p. 295-316.

FREIRE, P. Professora sim, tia não. Cartas a quem ousa ensinar. São Paulo: Olho d'Água, 1997.

FREIRE. P. Educação como prática da liberdade. Rio de Janeiro: Paz e Terra, 2010.

FREIRE, P. Pedagogia do Oprimido. Rio de Janeiro: Paz e Terra, 1987.

FREIRE, P. Pedagogia da Autonomia: saberes necessários à prática educativa. São Paulo: Paz e Terra, 1996.

Inter-Ação, Goiânia, v. 46, n. ed.especial, p. 1258-1275, set. 2021. Disponível em: <http://dx.doi.org/10.5216/ia.v46ied.especial.67896>. 
REZENDE, A.; OLIVEIRA, E. C. de zEN, E. T.; FERREIRA, M. J. de R.

FREIRE, P. Educação e atualidade brasileira. São Paulo: Cortez/IPF, 2001.

HOLLIDAY, O. J. Para sistematizar experiências. Brasília: MMA, 2006.

INSTITUTO FEDERAL DO ESPÍRITO SANTO (Ifes). PDI 2014 - 2019. Vitória: Ifes, 2018. Dis-

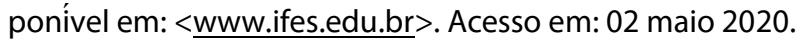

LIBÂNEO, J. C., \& FREITAS, R. M. Políticas educacionais neoliberais e escola pública: uma qualidade restrita de educação escolar. Goiânia: Ed. Espaço Acadêmico, 2018.

MACHADO. M. M. Quando atrofiar e desqualificar são condições para a manutenção da subalternidade. Cad. Pesq., p. 156-168, v. 26, n. 4, out./dez., 2019.

MACHADO, R. de C.; PALUDO, C. A sistematização como um dos métodos da Educação Popular. In: Anais Anped Sul, 2010. Disponível em: <http://www.portalanpedsul.com.br/admin/uploads/2010/educacao_e_movimentos_s ociais/trabalho/02_10_39_a_sistematizacao_como_um_dos_metodos_da_educacao_ popular.pdf>. Acesso em: 25 jul. 2014.

JIMENEZ, M. R. M. La sistematización como proceso investigativo. O la búsqueda de la episteme de lãs prácticas. 2009. Disponível em: <http://www.cepalforja.org/sistem/sistem_old/sistematizacion_como_proceso_investi gativo.pdf >. Acesso em: 24 mar. 2020.

MESSINA, G.; OSORIO, J. Sistematizar como ejercicio eco-reflexivo: la fuerza del relato en los procesos de sistematización de experiencias educativas. In: Revista e-Curriculum, São Paulo, v.14, n.02, p. 602 - 624 abr./jun.2016. Disponível em: <http://revistas.pucsp.br/index.php/curriculum>. Acesso: 25 mar. 2020.

SANTOS, M. Por uma outra globalização: do pensamento único à consciência universal. Rio de Janeiro: Record, 2000.

ALDO ReZende: Pós-doutorando na área de educação (UFES). Doutor em Planejamento Urbano e Regional-UFRJ. Mestre em Geografia-UFES. Mestre na área de Ciências Sociais: (turismo e hospitalidade) Universidade Anhembi Morumbi-SP. Especialista em Planejamento Educacional-Universo-RJ; Graduado em Geografia e História - PUC/MG e Faculdade de Ciências Humanas de Vitória. Professor do Ensino Básico, Técnico e Tecnológico do IFES-Campus Vitória.

Orcid: https://orcid.org/0000-0001-7239-1002

E-mail: aldo.rezende@ifes.edu.br

Edna Castro de Oliveira: Possui graduação em Pedagogia pela Universidade Federal do Espírito Santo (UFES - 1974), mestrado em Educação pela UFES em 1988, doutorado em Educação Brasileira pela Universidade Federal Fluminense (2005) e pós doutorado 
em Educação pela Universidade Federal do Espírito Santo (2017). Atualmente é professora associada da UFES.

Orcid: https://orcid.org/0000-0003-0798-7090

E-mail: oliveiraedna@yahoo.com.br

Eliesér TORETTA Zen: Doutor e mestre em educação pela Universidade Federal do Espírito Santo - UFES. Licenciado em Filosofia pela Pontifícia Universidade Católica de Minas Gerais (PUC/MG). Especialista em Filosofia Contemporânea e em educação pela UFES. Professor titular de filosofia do Instituto Federal de Educação, Ciência e Tecnologia do Espírito Santo - Ifes. Professor permanente e orientador do Programa de Pós-Graduação do Mestrado Profissional em Ensino de Humanidades (PPGEH).

Orcid: https://orcid.org/0000-0002-4705-1636

E-mail: elieserzen@ifes.edu.br

Maria José de Resende Ferreira: Graduada em História pela Universidade Federal do Ceará (1990). Especialista em História do Brasil (PUC/MG) e em Educação Profissional Técnica Integrada ao Ensino Médio na Modalidade de Educação de Jovens e Adultos (CEFETES). Mestre em Educação Profissional pelo Instituto Superior Pedagógico para a Educação Técnica e Profissional Hector A. Pineda Zaldivar Havana/Cuba, revalidado pela UFG (2003). Doutora em Educação pelo Programa de Pós-graduação em Educação da Universidade Federal do Espírito Santo (PPGE/CE/UFES) (2017). É professora efetiva do Instituto Federal de Educação Tecnológica do Espírito Santo.

Orcid: https://orcid.org/0000-0001-9442-0468

E-mail: majoresende@yahoo.com.br

Este periódico utiliza a licença Creative Commons Attribution 3.0, para periódicos de acesso aberto (Open Archives Initiative - OAI). 